Article

\title{
Enhancement of Electrical Characteristics and Stability of Amorphous Si-Sn-O Thin Film Transistors with $\mathrm{SiO}_{x}$ Passivation Layer
}

\author{
Xianzhe Liu ${ }^{1}$, Weijing Wu ${ }^{1}$, Weifeng Chen ${ }^{1}$, Honglong Ning ${ }^{1, *} \mathbb{1}$, Xiaochen Zhang ${ }^{1}$, \\ Weijian Yuan ${ }^{1}$, Mei Xiong ${ }^{1,2}$, Xiaofeng Wang ${ }^{3}$, Rihui Yao ${ }^{1, *(1)}$ and Junbiao Peng ${ }^{1}$ \\ 1 State Key Laboratory of Luminescent Materials and Devices, South China University of Technology, \\ Guangzhou 510640, China; msliuxianzhe@mail.scut.edu.cn (X.L.); wuwj@scut.edu.cn (W.W.); \\ chenweifengchn@foxmail.com (W.C.); zhangxc_scut@foxmail.com (X.Z.); g18826075867@163.com (W.Y.); \\ xiaochanglang@163.com (M.X.); psjbpeng@scut.edu.cn (J.P.) \\ 2 Shenzhen China Star Optoelectronics Technology Co., Ltd. (CSOT), Shenzhen 518132, China \\ 3 Institute of Semiconductors, Chinese Academy of Science, Beijing 100083, China; wangxiaofeng@semi.ac.cn \\ * Correspondence: ninghl@scut.edu.cn (H.N.); yaorihui@scut.edu.cn (R.Y.); Tel.: +86-20-8711-0606 (H.N.); \\ +86-20-8711-4346 (R.Y.)
}

Received: 21 June 2018; Accepted: 9 August 2018; Published: 15 August 2018

\begin{abstract}
In this research, a passivated methodology was proposed for achieving good electrical characteristics for back-channel-etch (BCE) typed amorphous Si-Sn-O thin film transistors (a-STO TFTs). This methodology implied that the thermal annealing (i.e., pre-annealing) should be carried out before deposition of a $\mathrm{SiO}_{\mathrm{x}}$ passivation layer. The pre-annealing played an important role in affecting device performance, which did get rid of the contamination of the lithography process. Simultaneously, the acceptor-like sub-gap density of states (DOS) of devices was extracted for further understanding the reason for improving device performance. It found that the $\mathrm{SiO}_{\mathrm{x}}$ layer could reduce DOS of the device and successfully protect the device from surroundings. Finally, a-STO TFT applied with this passivated methodology could possess good electrical properties including a saturation mobility of $4.2 \pm 0.2 \mathrm{~cm}^{2} / \mathrm{V}$ s, a low threshold voltage of $0.00 \mathrm{~V}$, a large on/off current ratio of $6.94 \times 10^{8}$, and a steep subthreshold swing of $0.23 \mathrm{~V} /$ decade. The threshold voltage slightly shifted under bias stresses and recovered itself to its initial state without any annealing procedure, which was attributed to the charge trapping in the bulk dielectric layers or interface. The results of this study indicate that a-STO TFT could be a robust candidate for realizing a large-size and high-resolution display.
\end{abstract}

Keywords: amorphous $\mathrm{Si}-\mathrm{Sn}-\mathrm{O}$ semiconductor; $\mathrm{SiO}_{x}$ passivation layer; density of states; stability

\section{Introduction}

Amorphous metal oxide semiconductors (AMOS) are attractive candidate materials for fabricating next-generation thin film transistors (TFTs), which can be used as the driving backplanes of active matrix liquid-crystal displays (AMLCD) and active matrix organic light-emitting diode (AMOLED) displays, due to their low-temperature process, high optical transparency in the visible region, high field effective mobility, low subthreshold swing, and high on/off current ratio [1,2]. Especially, amorphous In-Ga-Zn-O (a-IGZO) has been achieved in commercial application of AMLCD or AMOLED products. With the advances in display technology, demands for large-size and high-resolution display products are increasing. The fabrication of miniaturized TFT with the back-channel-etch (BCE) technique can meet the demands of large-size and high-resolution display panels. However, the development of miniaturized AMOS TFTs is sluggish because oxide 
semiconductors are sensitive to weak acid etchant, causing damage to the back-channel surface of the device. Thus, exploiting an acid-resistant and stable active layer material is one potential solution for fabricating BCE typed TFTs. Various kinds of oxide semiconductors have sprung up and been widely researched in order to achieve an excellent device performance since a-IGZO was reported $[3,4]$. Among these oxide semiconductors, tin oxide $\left(\mathrm{SnO}_{2}\right)$, with high chemical stability, low cost, and nontoxicity, was proposed as one of the promising candidates for fabricating BCE typed devices to enable high resolution $[5,6]$. However, due to polycrystalline structure and high carrier concentration of the intrinsic $\mathrm{SnO}_{2}$, the application of TFT backplane is limited. Recently, the doping element of silicon (Si) was successfully demonstrated to be an excellent carrier suppressor in oxide semiconductors that were used for electron injection/transport of OLED [7], the formation of Schottky contact in IGZO-TFT [8], and the active layers in oxide TFTs [9]. It is well known that the charge carriers in the oxide semiconductors can be related to the oxygen vacancy. For $\mathrm{SnO}_{2}$, the oxygen vacancy can be suppressed by the Si element because oxygen bond-dissociation energy of Si-O $(799.6 \mathrm{~kJ} / \mathrm{mol})$ is stronger than that of $\mathrm{Sn}-\mathrm{O}(531.8 \mathrm{~kJ} / \mathrm{mol})$, which can prevent the oxygen atoms from getting out of the $\mathrm{SnO}_{2}$ film during the sputtering or annealing process [10-12].

For integrated circuit applications of oxide TFTs, the passivation layer plays a critical role in protecting devices from surroundings. Generally, oxide semiconductors are susceptible to oxygen or water molecules in the ambient atmosphere. The adsorption/desorption dynamic of $\mathrm{O}_{2}$ or $\mathrm{H}_{2} \mathrm{O}$ molecules on the back-channel region of the device affects the properties of oxide TFT [13]. The adsorbed oxygen captures electrons from the channel layer, which results in a positive $V_{\text {th }}$ shift in oxide TFTs $\left(\mathrm{O}_{2(\mathrm{~g})}+\mathrm{e}^{-} \leftrightarrow \mathrm{O}_{2(\mathrm{~s})}^{-}\right)$. The absorbed water molecules can be charged and generate excess electrons into the channel layer, which leads to a negative $V_{\text {th }}$ shift in oxide TFTs $\left(\mathrm{H}_{2} \mathrm{O}_{(\mathrm{g})} \leftrightarrow \mathrm{H}_{2} \mathrm{O}_{(\mathrm{s})}^{+}+\mathrm{e}^{-}\right)$. Up until now, different species of organic and inorganic passivation layers, such as perfluoro (1-butenyl vinyl ether) polymer (CYTOP) [14], silicon nitride $\left(\mathrm{SiN}_{\mathrm{x}}\right)$ [15], and silicon oxide $\left(\mathrm{SiO}_{x}\right)$ [16] have been widely studied. The diffusion barrier properties against $\mathrm{O}_{2}$ and $\mathrm{H}_{2} \mathrm{O}$ molecules in the ambient of organic passivation layers are lower than that of inorganic passivation layers on account of their high permeability of ambient gas. Although the diffusion barrier properties of $\mathrm{SiN}_{\mathrm{x}}$ against $\mathrm{O}_{2}$ and $\mathrm{H}_{2} \mathrm{O}$ molecules in the ambient are better than that of $\mathrm{SiO}_{\mathrm{x}}$, the generation of hydrogen concentration in $\mathrm{SiN}_{\mathrm{x}}$ is higher than that of $\mathrm{SiO}_{\mathrm{x}}$ during the deposition by plasma enhanced chemical vapor deposition (PECVD), which can deteriorate device performance and stability [17].

In this paper, comparison of the electrical characteristics of BCE typed a-STO TFTs, with and without thermal annealing before deposition of $\mathrm{SiO}_{\mathrm{x}}$, was carried out. It demonstrated that the pre-annealing was an important step for enhancing electrical properties of the device. The reason for achieving good electrical properties of a-STO TFTs with $\mathrm{SiO}_{\mathrm{x}}$ passivation was investigated in detail.

\section{Materials and Methods}

The cross-sectional configuration schematic of a-STO TFTs with BCE structure was fabricated on glass substrates, as illustrated in Figure 1. First, a $300 \mathrm{~nm}$ thick Al-Nd alloy ( $3 \mathrm{wt} \% \mathrm{of} \mathrm{Nd}$ ) was deposited on glass substrate and patterned as a gate electrode. Second, a $200 \mathrm{~nm}$ thick gate insulator layer of $\mathrm{AlO}_{x}-\mathrm{Nd}$ was formed using the anodization process. Third, an ultra-thin $5 \mathrm{~nm}$ a-STO film was deposited by using a ceramic target $\left(\mathrm{SiO}_{2}: \mathrm{SnO}_{2}=5: 95 \mathrm{wt} \%\right)$ with a power of $300 \mathrm{~W}$, an argon/oxygen flow ratio of $20 / 2 \mathrm{sccm}$ and a pressure of 2 mtorr at room temperature, and patterned by a lift-off process. Fourth, a $200 \mathrm{~nm}$ Mo film used for the Source/Drain (S/D) electrodes was sputtered at room temperature and the channel width/length $(100 / 50 \mu \mathrm{m})$ was defined using the wet etch process. Fifth, the passivation-free Device A was fabricated. Finally, two passivation process approaches of $300 \mathrm{~nm}$ $\mathrm{SiO}_{\mathrm{x}}$ deposited by PECVD at $300{ }^{\circ} \mathrm{C}$ were conducted, respectively. A layer of $\mathrm{SiO}_{\mathrm{x}}$ film was directly deposited on the top of Device A, which was called Device B. The channel region of Device A was covered by a $\mathrm{SiO}_{\mathrm{x}}$ layer after being annealed at $350{ }^{\circ} \mathrm{C}$ in air ambient for $0.5 \mathrm{~h}$, which resulted in the formation of Device C (See Figure S1). 


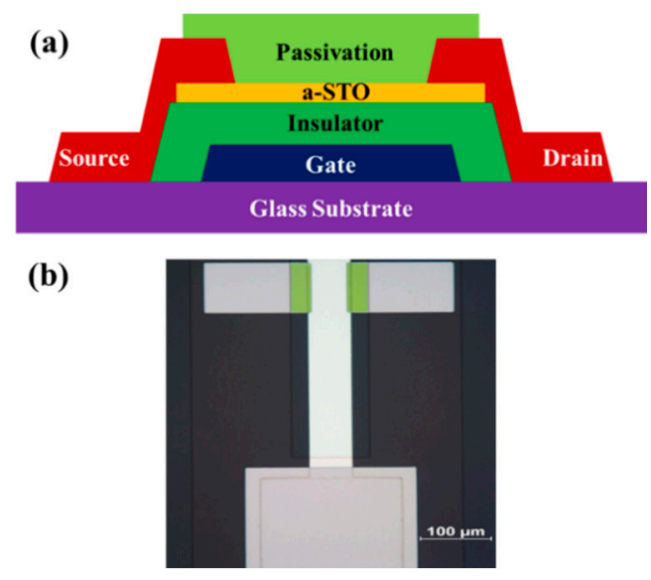

Figure 1. (a) Schematics configuration of back-channel etching type a-STO TFT. (b) Optical top view image of a-STO TFT. TFT channel width/length is $100 \mu \mathrm{m} / 50 \mu \mathrm{m}$.

Metal electrodes were prepared by direct current (DC) magnetron sputtering and a-STO films were deposited by radio frequency (RF) Magnetron sputtering (Kurt J. Lesker, Jefferson Hills, MA, USA). Morphology and roughness of a-STO film deposited on the glass substrate were obtained by atomic force microscope (AFM, Multimode 8, Bruker, Karlsruhe, Germany) measurement. The density and thickness were analyzed by $X$-ray reflectivity (XRR, EMPYREAN, PANalytical, Almelo, The Netherlands). The oxygen vacancies of the channel layer were measured by $\mathrm{X}$-ray photoelectron spectroscopy (XPS, Escalab 250XI, Thermo Scientific, Waltham, MA, USA). The electrical characteristics and stability of device under gate bias stress were measured in air ambient by an Agilent 4155C semiconductor parameter analyzer (Agilent, Santa Clara, CA, USA). The applied positive bias stress (PBS) and negative bias stress (NBS) were as follows: $V_{\mathrm{GS}}= \pm 20 \mathrm{~V}$ and $\mathrm{V}_{\mathrm{DS}}=0 \mathrm{~V}$, which was applied for $3600 \mathrm{~s}$. The transfer characteristic curves of the device were tested when the gate biases were interrupted at fixed times. $V_{\text {th }}$ was extracted from the linear extrapolation of the plot of the square root of the drain current with gate voltage. And the recovery of $\mathrm{V}_{\text {th }}$ was also investigated in the dark after bias stress for $3600 \mathrm{~s}$. The transfer characteristic curves of TFT were measured after $1200 \mathrm{~s}$ intervals. Capacitance-voltage (C-V) curves of a-STO TFTs were measured by a KEYSIGHT E4990A Impedance Analyzer (Keysight Technologies Inc., Santa Rosa, CA, USA) with a fixed frequency of $10 \mathrm{k} \mathrm{Hz}$. The 2D device simulator ATLAS (Silvaco Inc., Santa Clara, CA, USA) was used for device simulation.

\section{Results and Discussion}

Figure 2a shows the representative transfer characteristic curves $\left(\mathrm{I}_{\mathrm{DS}}-\mathrm{V}_{\mathrm{GS}}\right)$ of as-deposited a-STO TFTs. There were many intrinsic defects at the semiconductor/insulator interface or in the a-STO active layer film for as-deposited Device A, which led to the generation of poor electrical performance, such as a large subthreshold swing (SS) and a large hysteresis. An evident increase of OFF current $\left(\mathrm{I}_{\text {off }}\right)$ and negative shift of turn-on voltage $\left(\mathrm{V}_{\text {on }}\right)$ were found after the channel region of the device was covered by a $\mathrm{SiO}_{x}$ passivation layer. Generally, the channel current $\left(\mathrm{I}_{\text {front }}\right)$ of the device cannot be affected by a passivation layer [18]. Thus, the increase of $\mathrm{I}_{\text {off }}$ in the passivated device was attributed to the byproduct hydrogen during the deposition of $\mathrm{SiO}_{\mathrm{x}}$. Because neutral $\mathrm{H}^{0}$ could migrate in the channel layer and further react with $\mathrm{O}^{2-}$ to form $\mathrm{OH}^{-}$and generate excessive electrons $\left(\mathrm{H}^{0}+\mathrm{O}^{2-} \rightarrow \mathrm{OH}^{-}+\mathrm{e}^{-}\right)$, which would result in the formation of back-channel current $\left(\mathrm{I}_{\text {back }}\right)$, as shown in Figure 2b [19]. 
(a)

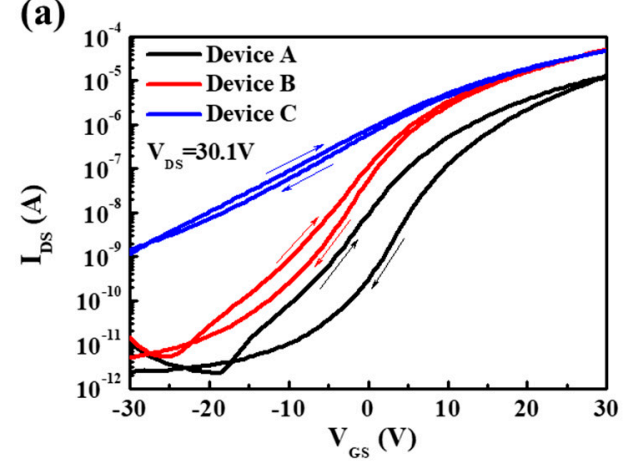

(c)

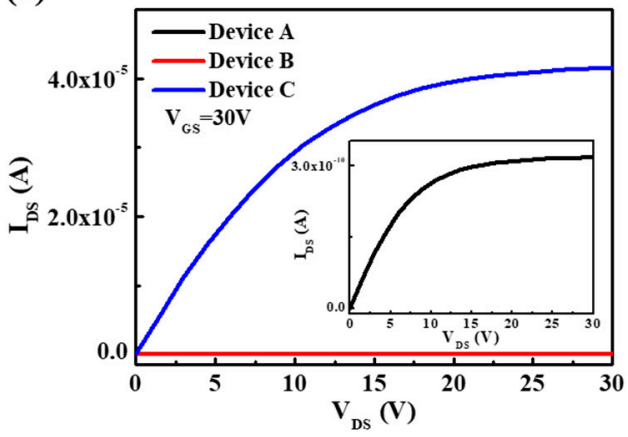

(b)

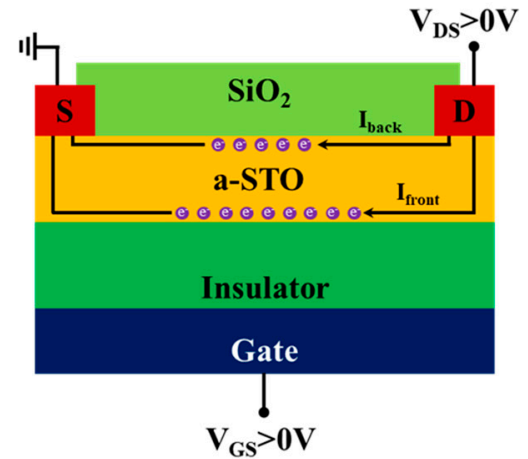

(d)

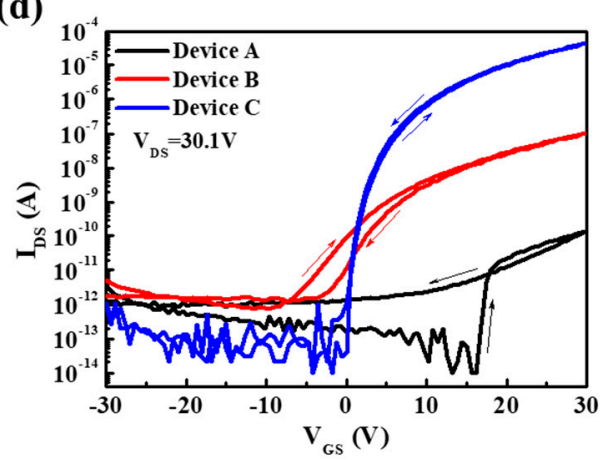

Figure 2. (a) The transfer characteristic curves of as-deposited a-STO TFTs when $\mathrm{V}_{\mathrm{DS}}$ was fixed at $30.1 \mathrm{~V}$; (b) Schematic of current paths of as-deposited a-STO TFT; (c) The drain current of a-STO TFTs annealed at $450^{\circ} \mathrm{C}$ for $0.5 \mathrm{~h}$ in argon ambient when $\mathrm{V}_{\mathrm{GS}}$ was fixed at $30 \mathrm{~V}$; (d) The transfer characteristic curves of a-STO TFTs annealed at $450{ }^{\circ} \mathrm{C}$ for $0.5 \mathrm{~h}$ in argon ambient when $\mathrm{V}_{\mathrm{DS}}$ was fixed at $30.1 \mathrm{~V}$.

To obtain good performance of a-STO TFTs, an additional thermal post-annealing in argon ambient for devices was inevitably carried out. The I-V curves of both Device A $\left(\sim 10^{-10} \mathrm{~A}\right)$ and Device B $\left(\sim 10^{-8} \mathrm{~A}\right)$ were approximate to a horizontal line compared with that of device $\mathrm{C}\left(\sim 10^{-5} \mathrm{~A}\right)$, as illustrated in Figure 2c. Figure $2 \mathrm{~d}$ exhibits the transfer characteristic curves of devices with thermal post-annealing. The transfer characteristics of Device A and Device B were not improved by post-annealing. The channel layer of Device A was terribly transformed into an insulator-like layer. For the transfer curve of Device B, the hysteresis unexpectedly was still maintained and the reduction of ON current $\left(\mathrm{I}_{\mathrm{on}}\right)$ also occurred. Fortunately, a good device performance was successfully achieved in Device C. The field-effect mobility in the saturation region of the device and the subthreshold swing (SS) were extracted by using the following equations [1]:

$$
\begin{gathered}
I_{D S}=\frac{W \mu_{\text {sat }} C_{i}}{2 L}\left(V_{G S}-V_{\text {th }}\right)^{2} \\
S S=\left(\frac{d \log \left(I_{D S}\right)}{d V_{G S}}\right)^{-1}
\end{gathered}
$$

where $\mathrm{I}_{\mathrm{DS}}$ is the drain current, $\mathrm{V}_{\mathrm{DS}}$ is the drain voltage, $\mathrm{V}_{\mathrm{GS}}$ is the gate voltage, $\mathrm{V}_{\text {th }}$ is the threshold voltage, $\mathrm{W} / \mathrm{L}$ is the channel width/length, and $\mathrm{C}_{\mathrm{i}}$ is the gate capacitance per unit area of the insulator layer, respectively. The electrical parameters of devices with the post-annealing process, including saturation mobility $\left(\mu_{\text {sat }}\right)$, turn-on voltage $\left(V_{\text {on }}\right)$, on / off current ratio $\left(\mathrm{I}_{\text {on }} / \mathrm{I}_{\text {off }}\right)$, and subthreshold swing (SS) were listed in Table 1. A large $\mu_{\text {sat }}$ of $4.2 \pm 0.2 \mathrm{~cm}^{2} / \mathrm{V} \mathrm{s}$, a low $\mathrm{V}_{\text {on }}$ of $0.00 \mathrm{~V}$, a large $\mathrm{I}_{\mathrm{on}} / \mathrm{I}_{\text {off }}$ of $6.94 \times 10^{8}$, and a low SS of $0.23 \mathrm{~V} /$ decade were obtained in Device C. 
Table 1. Electrical parameters of a-STO TFTs with post-annealing in argon ambient.

\begin{tabular}{ccccc}
\hline Sample & $\boldsymbol{\mu}_{\text {sat }}\left(\mathbf{c m}^{2} / \mathbf{V} \mathbf{s}\right)$ & $\mathbf{V}_{\text {on }}(\mathbf{V})$ & $\mathbf{I}_{\text {on }} / \mathbf{I}_{\text {off }}$ & SS (V/decade) \\
\hline Device A & - & - & - & - \\
Device B & - & -9.55 & $1.37 \times 10^{5}$ & 3.39 \\
Device C & $4.2 \pm 0.2$ & 0.00 & $6.94 \times 10^{8}$ & 0.23 \\
\hline
\end{tabular}

$\mu_{\text {sat }}$ : saturation mobility, $\mathrm{V}_{\mathrm{on}}$ : turn-on voltage, $\mathrm{I}_{\mathrm{on}} / \mathrm{I}_{\text {off }}$ : on/off current ratio, SS: subthreshold swing.

The results of device performance implied that the pre-annealing played an important role in affecting the electrical properties of passivated device. An in-depth investigation of the thermal pre-annealing for Device A was performed. Figure 3 shows AFM images and XRR curves of $5 \mathrm{~nm}$ a-STO films. After a-STO film was annealed at $350{ }^{\circ} \mathrm{C}$ in air ambient for $0.5 \mathrm{~h}$, the roughness reduced from $0.192 \mathrm{~nm}$ to $0.167 \mathrm{~nm}$, while the density of a-STO film increased from $5.02 \mathrm{~g} / \mathrm{cm}^{3}$ to $5.41 \mathrm{~g} / \mathrm{cm}^{3}$. The thermal annealing process could facilitate the atoms' rearrangement and structural relaxation to reduce internal defects and improve the quality of film.

(a)

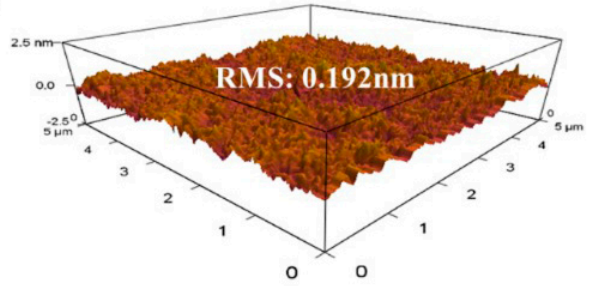

(b)

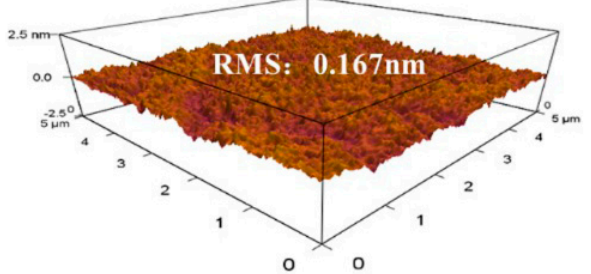

(c)
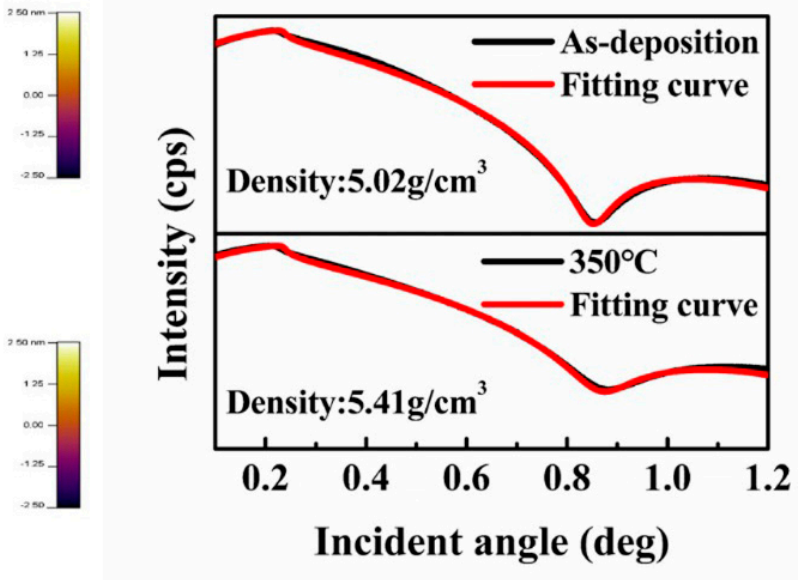

Figure 3. AFM images $(5 \times 5 \mu \mathrm{m})$ of $5 \mathrm{~nm}$ a-STO films: (a) as-deposition and (b) $350{ }^{\circ} \mathrm{C}$. (c) The XRR curves of $5 \mathrm{~nm}$ a-STO films.

Currently, oxygen vacancies are closely related to the field-effect mobility and threshold voltage of metal-oxide-semiconductor devices, according to the equation: $\mathrm{O}_{\mathrm{O}}^{\mathrm{X}}=\frac{1}{2} \mathrm{O}_{2(\mathrm{~g})}+\mathrm{V}_{\mathrm{O}}^{* *}+2 \mathrm{e}^{-}[20]$. The XPS analysis of the channel region was implemented, as displayed in Figure 4. All binding energies were corrected by referencing to the $\mathrm{C} 1$ s peak (centered at $284.8 \mathrm{eV}$ ). From the $\mathrm{C} 1 \mathrm{~s}$ spectra in Figure $4 \mathrm{a}$, it clearly revealed that the photoresist was not thoroughly eliminated in the channel region of as-deposited devices. And the contamination was dramatically eliminated in the channel region after being annealed at $350^{\circ} \mathrm{C}$ in air ambient. The O1s peak of a-STO channel layer could be de-convoluted into three principal sub-peaks via using a Gaussian-Lorentzian profile, which centered at $530.5 \pm 0.3 \mathrm{eV}$ (peak A), $531.8 \pm 0.2 \mathrm{eV}$ (peak B), and $532.7 \pm 0.1 \mathrm{eV}$ (peak C), respectively. The lowest binding energy located at $530.5 \pm 0.3 \mathrm{eV}$ was associated with oxygen-lattice bonds ( $\mathrm{Sn}-\mathrm{O}$ and $\mathrm{Si}-\mathrm{O}$ ) in a-STO compound system. The middle binding energy, centered at $531.8 \pm 0.2 \mathrm{eV}$, was assigned to the oxygen vacancies. The highest binding energy positioned at $532.7 \pm 0.1 \mathrm{eV}$ was usually attributed to the presence of loosely bound oxygen on species, with a surface of the a-STO film such as $-\mathrm{CO}_{3}$, - $\mathrm{OH}$ or adsorbed $\mathrm{O}_{2}$. After the unpassivated device was annealed at $350{ }^{\circ} \mathrm{C}$, a distinct increased area proportion of $\mathrm{V}_{\mathrm{B}}(\mathrm{B} /(\mathrm{A}+\mathrm{B}+\mathrm{C}))$, from $33.60 \%$ to $37.64 \%$, and an obvious decreased proportion of $\mathrm{V}_{\mathrm{C}}$ $(C /(A+B+C))$, from $8.66 \%$ to $5.30 \%$, were found. These results indicated that the pre-annealing could not only effectively remove the contamination but also facilitate the increase of carrier concentration. 
(a)

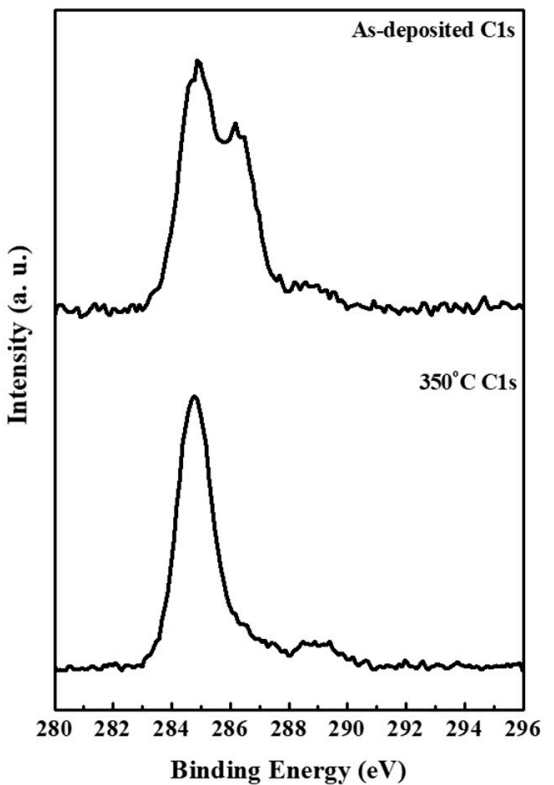

(b)

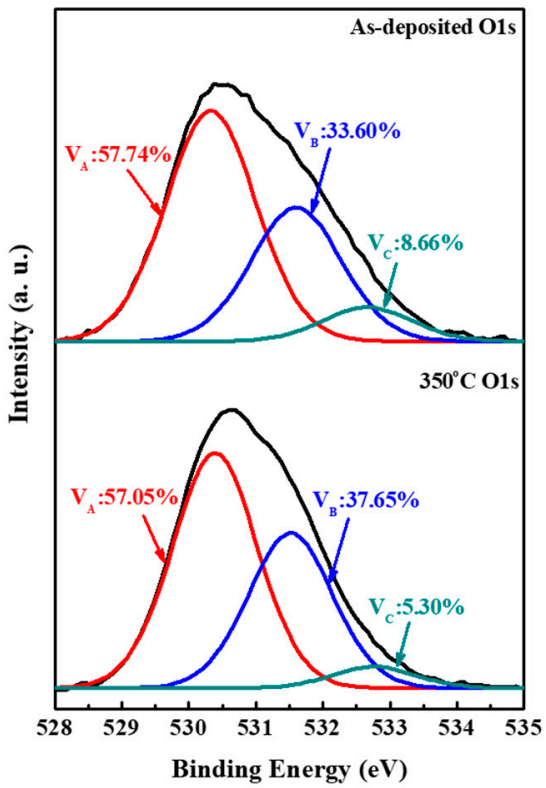

Figure 4. Comparison of XPS spectra in the channel region of Device A with/without thermal annealing process of $350{ }^{\circ} \mathrm{C}$ in air ambient: (a) C1s spectra and (b) O1s spectrum.

In AMOS devices, the sub-gap density of states (DOS) is an important parameter closely related to the mobility, operation voltage, and subthreshold swing of TFTs. To gain an insight into the reason for a series of changes in device performance, the acceptor-like DOS of a-STO TFTs was extracted by a low-frequency capacitance-voltage (C-V) characteristic [21]. The results of $\mathrm{C}-\mathrm{V}$ characteristics and DOS of a-STO TFTs were exhibited in Figure 5. The DOS of devices might be divided into two parts: deep states and tail states, which could be approximately represented by the superposition of the exponential tail states and exponential deep states:

$$
N_{t}(E)=N_{D A} \exp \left(\frac{E-E_{c}}{E_{D A}}\right)+N_{T A} \exp \left(\frac{E-E_{c}}{E_{T A}}\right)
$$

where $\mathrm{N}_{\mathrm{DA}}, \mathrm{N}_{\mathrm{TA}}, \mathrm{E}_{\mathrm{DA}}, \mathrm{E}_{\mathrm{TA}}, \mathrm{E}$, and $\mathrm{E}_{\mathrm{C}}$ is the density of deep states, the density of tail states, the energy of deep states, the energy of tail states, the state energy, and the conduction band minimum, respectively. The $\mathrm{N}_{\mathrm{DA}} / \mathrm{N}_{\mathrm{TA}}$ is extracted by extrapolating the deep/tail states to $\mathrm{E}=\mathrm{E}_{\mathrm{C}}$, while $\mathrm{E}_{\mathrm{DA}} / \mathrm{E}_{\mathrm{TA}}$ is extracted from the slope of $\log \left(\mathrm{N}_{\mathrm{t}}\right)$ versus $\left(\mathrm{E}-\mathrm{E}_{\mathrm{c}}\right)$ for the deep/tail states. The fitting results of DOS of a-STO TFTs were shown in Table 2. The density of deep/tail states $\left(2.02 \times 10^{18} / 4.61 \times 10^{20} \mathrm{~cm}^{-3} \mathrm{eV}^{-1}\right)$ of Device A annealed at $350^{\circ} \mathrm{C}$ in air ambient was obtained (See Figure S2). The passivation layer could effectively degrade DOS of device. Quantities of defects were generated in the Device A and Device $\mathrm{B}$ after they were annealed at $450{ }^{\circ} \mathrm{C}$ in argon ambient, which led to the deterioration of device performance. For Device C, the density of deep states decreased from $1.97 \times 10^{16} \mathrm{~cm}^{-3} \mathrm{eV}^{-1}$ to $1.44 \times 10^{16} \mathrm{~cm}^{-3} \mathrm{eV}^{-1}$ after thermal post-annealing, while the density of tail states increased from $0.73 \times 10^{17} \mathrm{~cm}^{-3} \mathrm{eV}^{-1}$ to $1.13 \times 10^{17} \mathrm{~cm}^{-3} \mathrm{eV}^{-1}$. The reason for the decrease of density of deep states was attributed to the reduction of excess oxygen in a-STO film [22]. Due to the existence of nonstoichiometric $\mathrm{SiO}_{x}$, excess oxygen in the bulk a-STO film was attracted to the $\mathrm{SiO}_{\mathrm{x}} / \mathrm{a}-\mathrm{STO}$ interface after post-annealing (See Figure S3). The increase of density of tail states might be associated with the elimination of hydrogen $\left(\mathrm{OH}^{-} \rightarrow \mathrm{H}^{\mathrm{o}}+\mathrm{O}^{-}\right)$because the $\mathrm{O}^{-}$ion can capture electrons to form stable $\mathrm{O}^{2-}$. 
(a)

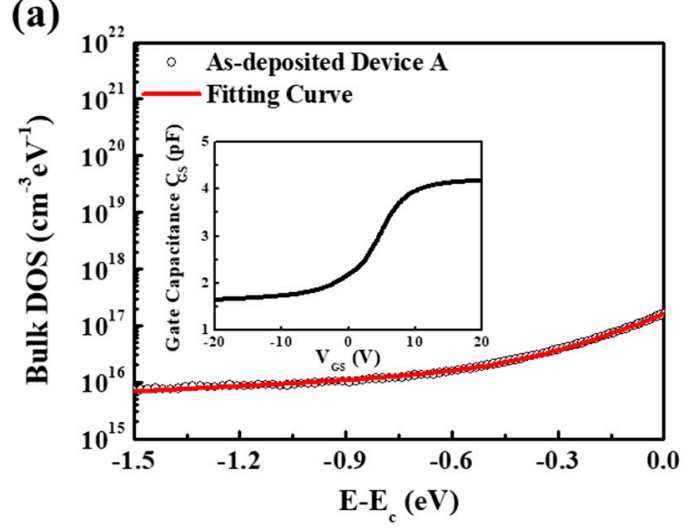

(c)

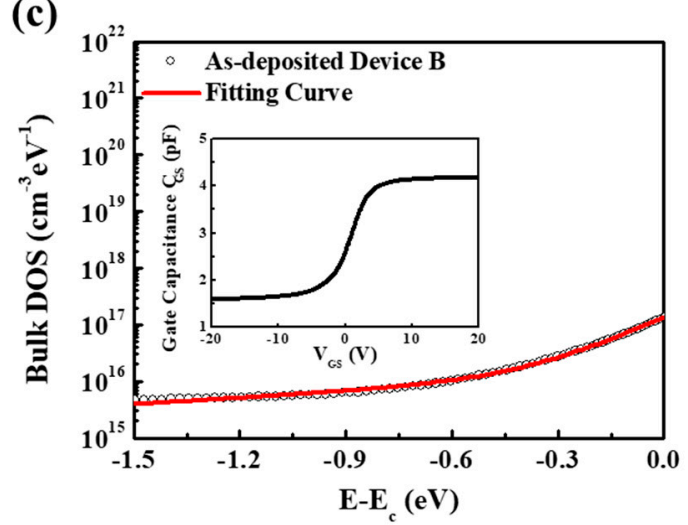

(e)

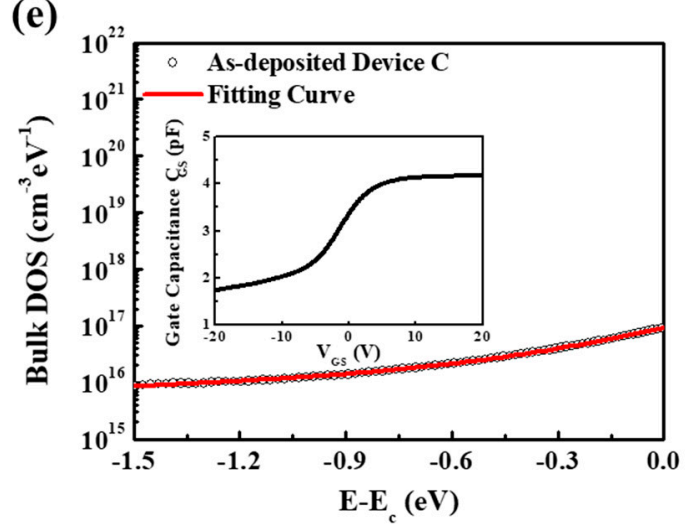

(b)

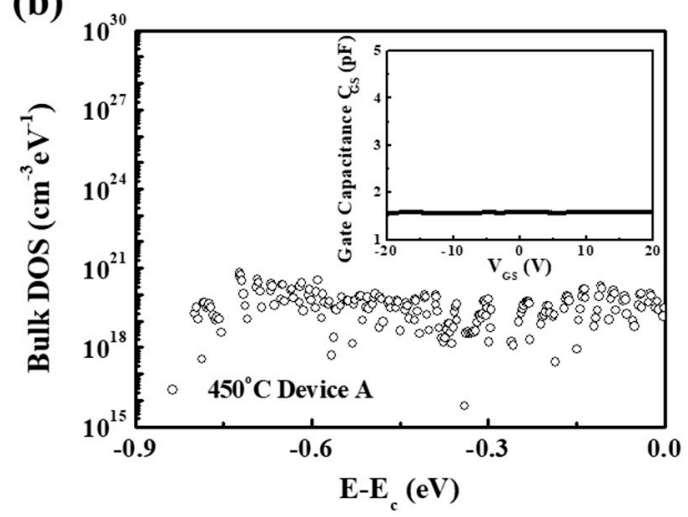

(d)

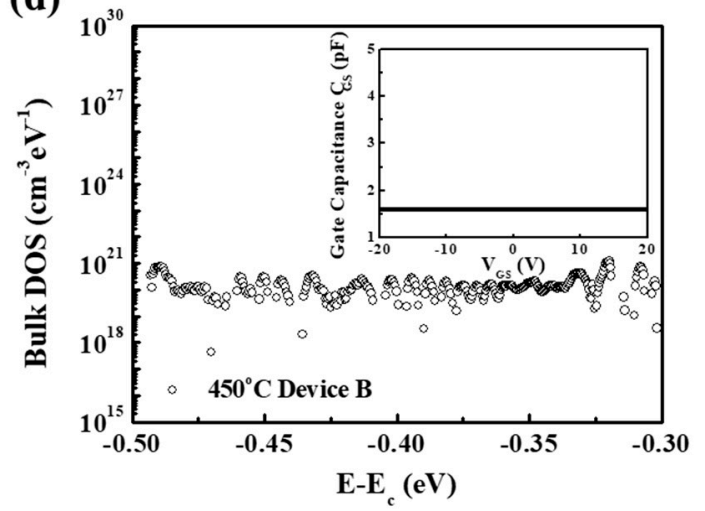

(f)

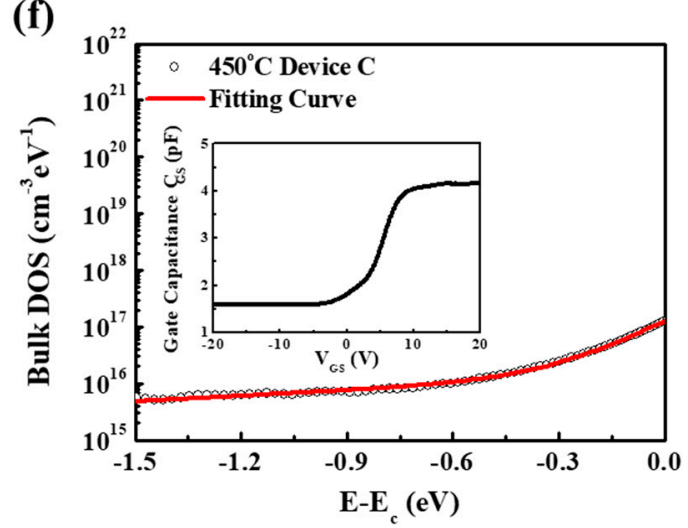

Figure 5. Extracted DOS of a-STO TFTs as function of E - $\mathrm{E}_{\mathrm{c}}$ : (a) as-deposited Device A, (b) $450{ }^{\circ} \mathrm{C}$ Device A, (c) as-deposited Device B, (d) $450{ }^{\circ} \mathrm{C}$ Device B, (e) as-deposited Device C and (f) $450{ }^{\circ} \mathrm{C}$ Device $\mathrm{C}$. Inset is $\mathrm{C}-\mathrm{V}$ curve of the corresponding a-STO TFT at $10 \mathrm{k} \mathrm{Hz}$.

Table 2. Comparison of DOS parameters of a-STO TFTs.

\begin{tabular}{ccccc}
\hline Samples & $\mathbf{N}_{\mathrm{DA}}\left(\mathrm{cm}^{-3} \mathbf{e V}^{-1}\right)$ & $\mathbf{E}_{\mathrm{DA}}(\mathbf{e V})$ & $\mathbf{N}_{\mathrm{TA}}\left(\mathrm{cm}^{-3} \mathbf{e V}^{-\mathbf{1}}\right)$ & $\mathbf{E}_{\mathrm{TA}}(\mathbf{e V})$ \\
\hline as-deposited Device A & $1.96 \times 10^{16}$ & 1.41 & $1.41 \times 10^{17}$ & 0.16 \\
$450^{\circ} \mathrm{C}$ Device A & - & - & - & - \\
\hline as-deposited Device B & $1.40 \times 10^{16}$ & 1.18 & $1.20 \times 10^{17}$ & 0.15 \\
$450^{\circ} \mathrm{C}$ Device B & - & - & - & - \\
\hline as-deposited Device C & $1.97 \times 10^{16}$ & 1.73 & $0.73 \times 10^{17}$ & 0.26 \\
$450^{\circ} \mathrm{C}$ Device C & $1.44 \times 10^{16}$ & 1.38 & $1.13 \times 10^{17}$ & 0.13 \\
\hline
\end{tabular}


The electrical stability is a very important parameter for AMOS-TFTs backplane in display. The investigation of PBS and NBS electrical instabilities of Device $C$ was performed, as illustrated in Figure $6 a, b$. The threshold voltage shift $\left(\Delta \mathrm{V}_{\text {th }}\right)$ under stress phase was $1.42 \mathrm{~V}$ (PBS) and $-1.48 \mathrm{~V}$ (NBS), respectively. After both bias stresses were applied, the $V_{\text {th }}$ of device could spontaneously recover to its initial state after a period of relaxation of $4800 \mathrm{~s}$. It is well known that there are two major mechanisms causing $\mathrm{V}_{\text {th }}$ instability: (1) defect creation in the channel and (2) charge trapping in the gate insulator and/or at the channel/insulator interface [23]. The negligible variation of mobility and SS (Figure 6c) and the recovery of $V_{\text {th }}$ without any annealing procedure (Figure $6 \mathrm{~d}$ ) after relaxation indicated that the charge trapping in the bulk dielectric layers or interface was the dominant mechanism responsible for $V_{\text {th }}$ instability. Thus, the charge trapping model could be reflected in the stress time dependence of $\Delta \mathrm{V}_{\text {th }}$, well-fitted with the stretched-exponential equation [24]:

$$
\Delta \mathrm{V}_{\text {th }}=\Delta \mathrm{V}_{\text {th } 0}\left\{1-\exp \left[-\left(\frac{\mathrm{t}}{\tau}\right)^{\beta}\right]\right\}
$$

where $\Delta \mathrm{V}_{\text {th } 0}$ is the $\Delta \mathrm{V}_{\text {th }}$ at infinite time, $\mathrm{t}$ is the stress time, $\tau$ is the characteristic time constant for trapping, and $\beta$ is the stretched-exponential exponent, respectively. Figure 7 shows the fitting curves of time dependence of $\Delta \mathrm{V}_{\text {th }}$ under PBS and NBS conditions. The characteristic time constant $\tau$ was $6.99 \times 10^{7} \mathrm{~s}$ (PBS) and $1.45 \times 10^{3} \mathrm{~s}$ (NBS) while stretched-exponential exponent $\beta$ was 0.82 (PBS) and 0.47 (NBS), respectively.

(a)

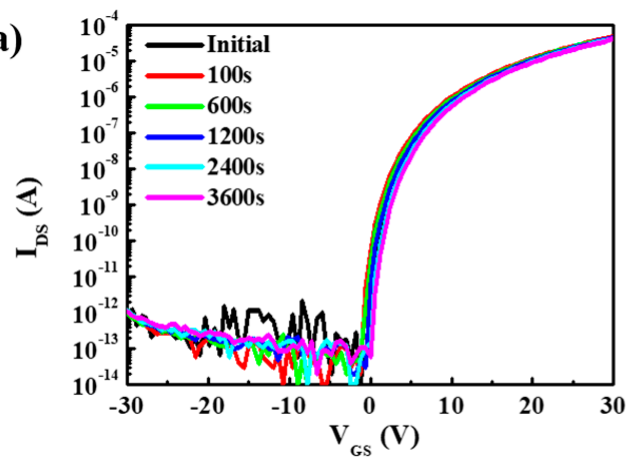

(c)

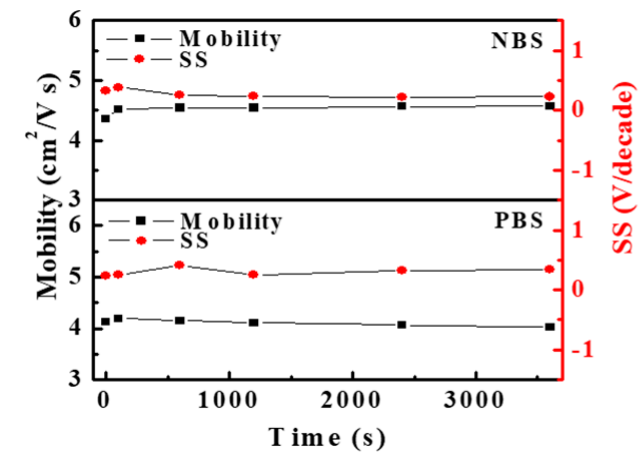

(b)

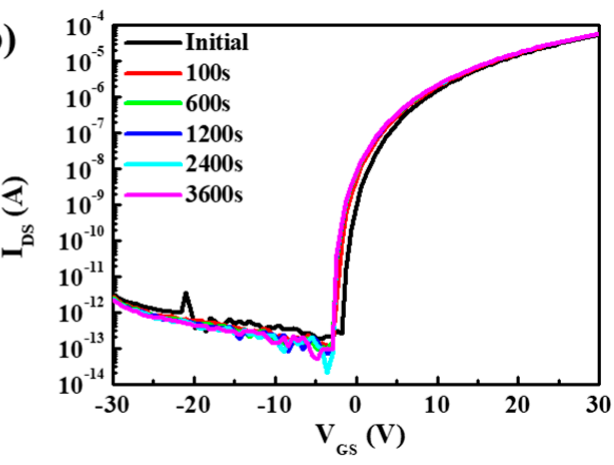

(d)

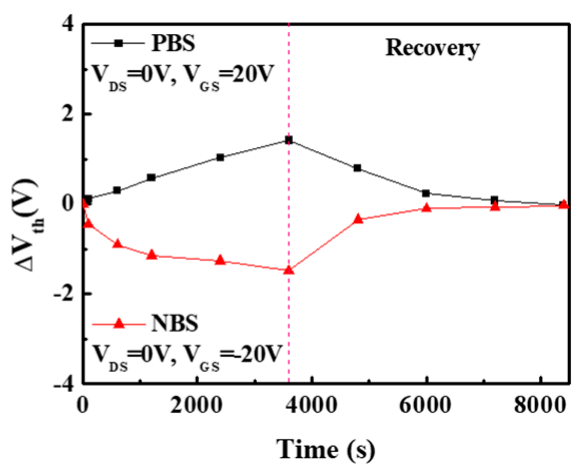

Figure 6. The evolution of transfer characteristic curves of device $\mathrm{C}$ annealed at $450{ }^{\circ} \mathrm{C}$ in vacuum argon ambient under (a) dark PBS condition and (b) dark NBS condition. (c) The change of mobility and SS of device $C$ as a function of stress time under PBS condition and NBS condition. (d) Variation in the $V_{\text {th }}$ value as a function of stress time and recovery time. The pink dash line is at the position of $3600 \mathrm{~s}$. 
(a)

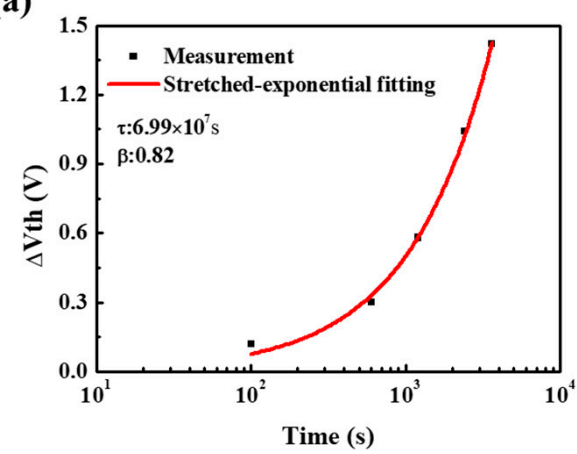

(b)

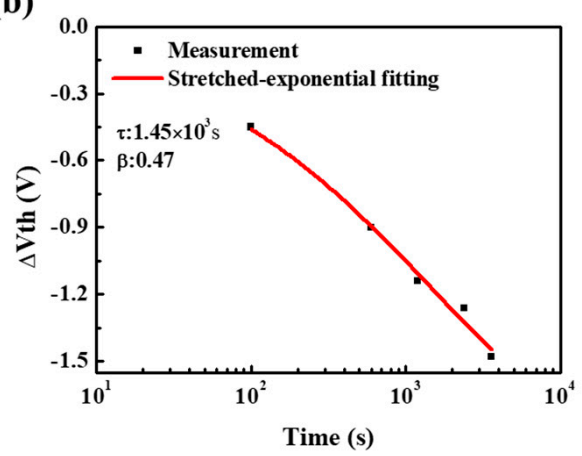

Figure 7. Time evolution of $\Delta V_{\text {th }}$ under different bias stresses: (a) PBS and (b) NBS. The measured data was well fitted with a stretched-exponential equation in both phases.

\section{Conclusions}

In summary, a good performance and stability of a-STO TFTs with BCE-typed structure was achieved by covering a $\mathrm{SiO}_{x}$ passivation layer. The thermal pre-annealing was an important factor for influencing device performance. It could effectively remove the contamination in the back-channel region of the device. The threshold voltage shift $\left(\Delta \mathrm{V}_{\mathrm{th}}\right)$ of a-STO TFTs was $1.42 \mathrm{~V}$ (PBS) and $-1.48 \mathrm{~V}$ (NBS) with slight variation of mobility and SS under PBS and NBS conditions, respectively. The time-evolution $\Delta \mathrm{V}_{\text {th }}$ of a-STO TFT under different stresses were well fitted by the stretched-exponential equation. After applied bias stress, the $V_{\text {th }}$ of the device could spontaneously recover to its initial state after a period of relaxation of $4800 \mathrm{~s}$. The reason for the instabilities of a-STO TFTs was attributed to the charge trapping in the bulk dielectric layers or interface. The results of this study show that a good performance and stability of a-STO TFTs represent good potential for display applications.

Supplementary Materials: The following are available online at http:/ /www.mdpi.com/1996-1944/11/8/1440/ s1, Figure S1: The fabricated three samples: Device A, Device B and Device C, respectively. Figure S2: (a) The transfer characteristic curve of Device A annealed at $350{ }^{\circ} \mathrm{C}$ in air ambient. (b) DOS extraction of corresponding Device A. Figure S3: The cross-sectional image and EDS scan line data of the $\mathrm{SiO}_{\mathrm{x}} / \mathrm{a}-\mathrm{STO}$ interface in Device C with post-annealing process. Method: The procedure for the proposed extraction method is described as follows. Table S1: Change in parameters including Vth, $\mu_{\text {sat }}$ and SS of a TFT as a function of stress time for different bias stress conditions: (a) Positive bias stress and (b) Negative bias stress, respectively.

Author Contributions: Conceptualization, X.L.; Methodology, W.W. and W.C.; Software, W.C.; Validation, R.Y., H.N. and J.P.; Formal Analysis, X.L.; Investigation, X.Z. and W.Y.; Data Curation, M.X. and X.W.; Writing-Original Draft Preparation, X.L.; Supervision, R.Y. and H.N.; Project Administration, H.N. and J.P.

Funding: This research received no external funding.

Acknowledgments: This research was funded by National Key R\&D Program of China (No. 2016YFB0401504 and 2016YFF0203600), National Natural Science Foundation of China (Grant No. 51771074, 51521002 and U1601651), National Key Basic Research and Development Program of China (973 program, Grant No. 2015CB655004) Founded by MOST, Guangdong Natural Science Foundation (No. 2016A030313459 and 2017A030310028), Guangdong Science and Technology Project (No. 2016B090907001, 2016A040403037, 2016B090906002 and 2017A050503002), Guangzhou Science and Technology Project (201804020033), Equipment Research Fund of CAS (Laser annealing equipment Research for 3rd semiconductor materials and Si-based microelectronics application).

Conflicts of Interest: The authors declare no conflict of interest.

\section{References}

1. Fortunato, E.; Barquinha, P.; Martins, R. Oxide semiconductor Thin-Film Transistors: A Review of Recent Advances. Adv. Mater. 2012, 24, 2945-2986. [CrossRef] [PubMed]

2. Hosono, H. Recent Progress in Transparent Oxide Semiconductors: Materials and Device Application. Thin Solid Films 2007, 515, 6000-6014. [CrossRef]

3. Kamiya, T.; Nomura, K.; Hosono, H. Present Status of Amorphous In-Ga-Zn-O Thin-Film Transistors. Sci. Technol. Adv. Mater. 2010, 11, 044305. [CrossRef] [PubMed] 
4. Park, J.S.; Maeng, W.J.; Kim, H.S.; Park, J.S. Review of Recent Developments in Amorphous Oxide Semiconductor Thin-Film Transistor Devices. Thin Solid Films 2012, 520, 1679-1693. [CrossRef]

5. Jo, K.W.; Moon, S.W.; Cho, W.J. Fabrication of High-Performance Ultra-Thin-Body $\mathrm{SnO}_{2}$ Thin-Film Transistors Using Microwave-Irradiation Post-Deposition Annealing. Appl. Phys. Lett. 2015, 106, 043501. [CrossRef]

6. Zhai, J.; Zhang, X.; Hai, F.; Yu, X.; Zhu, R.; Zhang, W. Fabrication and Characterization of Thin-Film Transistors with $\mathrm{SnO}_{2}$ Channel by Spray Pyrolysis. Jpn. J. Appl. Phys. 2014, 53, 066506. [CrossRef]

7. Nakamura, N.; Kim, J.; Hosono, H. Material Design of Transparent Oxide Semiconductors for Organic Electronics: Why Do Zinc Silicate Thin Films Have Exceptional Properties? Adv. Electron. Mater. 2018, 4, 1700352. [CrossRef]

8. Kaczmarski, J.; Borysiewicz, M.A.; Piskorski, K.; Wzorek, M.; Kozubal, M.; Kamińska, E. Flexible IGZO Schottky diodes on paper. Semicond. Sci. Technol. 2018, 33, 015010. [CrossRef]

9. Mitoma, N.; Aikawa, S.; Gao, X.; Kizu, T.; Shimizu, M.; Lin, M.F.; Nabatame, T.; Tsukagoshi, K. Stable amorphous $\mathrm{In}_{2} \mathrm{O}_{3}$-based thin-film transistors by incorporating $\mathrm{SiO}_{2}$ to suppress oxygen vacancies. Appl. Phys. Lett. 2014, 104, 102103. [CrossRef]

10. Luo, Y.R. CRC Handbook of Chemistry and Physics; CRC Press: Boca Raton, FL, USA, 2012.

11. Ning, H.; Liu, X.; Zhang, H.; Fang, Z.; Cai, W.; Chen, J.; Yao, R.; Xu, M.; Wang, L.; Lan, L.; et al. Effect of Intrinsic Stress on Structural and Optical Properties of Amorphous Si-Doped $\mathrm{SnO}_{2}$ Thin-Film. Materials 2017, 10, 24. [CrossRef] [PubMed]

12. Yang, J.; Yang, Z.; Meng, T.; Han, Y.; Wang, X.; Zhang, Q. Effects of Silicon Doping on the Performance of Tin Oxide Thin Film Transistors. Phys. Status Solidi A 2015, 6, 1-6. [CrossRef]

13. Jeong, J.K.; Yang, H.W.; Jeong, J.H.; Mo, Y.; Kim, H.D. Origin of Threshold Voltage Instability in Indium-Gallium-Zinc Oxide Thin Film Transistors. Appl. Phys. Lett. 2008, 93, 123508. [CrossRef]

14. Choi, S.; Jang, J.; Kim, J.; Han, M. Low-Temperature Organic (CYTOP) Passivation for Improvement of Electric Characteristics and Reliability in IGZO TFTs. IEEE Electron Device Lett. 2012, 33, 381-383. [CrossRef]

15. Park, J.S.; Kim, T.S.; Son, K.S.; Lee, K.; Maeng, W.; Kim, H.; Kim, E.S.; Park, K.; Seon, J.; Choi, W.; et al. The Influence of SiOX and SiNX Passivation on the Negative Bias Stability of Hf-In-Zn-O Thin Film Transistors under Illumination. Appl. Phys. Lett. 2010, 96, 262109. [CrossRef]

16. Li, M.; Lan, L.; Xu, M.; Xu, H.; Luo, D.; Xiong, N.; Peng, J. Impact of Deposition Temperature of the Silicon Oxide Passivation on the Performance of Indium Zinc Oxide Thin-Film Transistors. Jpn. J. Appl. Phys. 2012, 51, 076501. [CrossRef]

17. Zhou, X.; Wang, G.; Shao, Y.; Zhang, L.; Lu, H.; Chen, S.; Han, D.; Wang, Y.; Zhang, S. Parylene $/ \mathrm{Al}_{2} \mathrm{O}_{3}$ Double Layer Passivated Amorphous InGaZnO Thin-Film Transistors. J. Soc. Inf. Disp. 2017, 48, 1258-1261.

18. Hong, D.; Wager, J.F.; Hong, D.; Wager, J.F. Passivation of Zinc-Tin-Oxide Thin-Film Transistors Passivation of Zinc-Tin-Oxide Thin-Film Transistors. J. Vac. Sci. Technol. B 2005, 23, 25-27. [CrossRef]

19. Bang, J.; Matsuishi, S.; Hosono, H. Hydrogen Anion and Subgap States in Amorphous In-Ga-Zn-O Thin Films for TFT Applications. Appl. Phys. Lett. 2017, 110, 232105. [CrossRef]

20. Liu, X.; Xu, H.; Ning, H.; Lu, K.; Zhang, H.; Zhang, X.; Yao, R.; Fang, Z.; Lu, X.; Peng, J. Induced Nano-Scale Self-Formed Metal-Oxide Interlayer in Amorphous Silicon Tin Oxide Thin Film Transistors. Sci. Rep. 2018, 8, 4160. [CrossRef] [PubMed]

21. Wu, W.-J.; Chen, C.-L.; Hu, X.; Xia, X.-H.; Zhou, L.; Xu, M.; Wang, L.; Peng, J.-B. Analytical Extraction Method for Density of States in Metal Oxide Thin-Film Transistors by Using Low-Frequency Capacitance-Voltage Characteristics. J. Disp. Technol. 2016, 12, 888-891. [CrossRef]

22. Yu, E.K.; Jun, S.; Kim, D.H.; Kanicki, J.; Yu, E.K.; Jun, S.; Kim, D.H.; Kanicki, J. Density of States of Amorphous In-Ga-Zn-O from Electrical and Optical Characterization Density of States of Amorphous In-Ga-Zn-O from Electrical and Optical Characterization. J. Appl. Phys. 2014, 116, 154505. [CrossRef]

23. Cross, R.B.M.; De Souza, M.M. Investigating the Stability of Zinc Oxide Thin Film Transistors. Appl. Phys. Lett. 2006, 89, 263513. [CrossRef]

24. Cho, I.T.; Lee, J.M.; Lee, J.H.; Kwon, H.I. Charge Trapping and Detrapping Characteristics in Amorphous InGaZnO TFTs under Static and Dynamic Stresses. Semicond. Sci. Technol. 2009, 24, 015013. [CrossRef] 